\title{
Mycelia growth inhibition of some Aspergillus and Fusarium species by essential oils and their potential use as antiradical agent
}

\author{
Yaouba Aoudou', Tatsadjieu ${ }^{2}$ Ngoune Léopold and Mbofung $^{1}$ Carl Moses
}

${ }^{1}$ Department of food Sciences and Nutrition, National Advanced School of Agro-industrial Sciences of University of Ngaoundere PO Box 454 Ngaoundere, Cameroon

${ }^{2}$ Laboratory of Microbiology, University Institute of Technology, University of Ngaoundere PO Box 455 Ngaoundere, Cameroon

\begin{abstract}
The essential oils extracted from Lippia rugosa and Plectranthus glandulosus leaves from Cameroon were analysed by GC-MS and evaluated for their antifungal activities against Aspergillus flavus, Aspergillus niger and Fusarium moniliforme common fungi causing spoilage of stored food product, and antiradical activities. The disc diffusion method was used to evaluate the fungal growth inhibition at various concentrations of oils while the antiradical activity was studied by the DPPH (diphenyl picryl hydrazyl) method. The main components found in P. glandulosus leaves oil were terpinolene $(30.8 \%)$, fenchone $(13.2 \%)$, terpene $4-0$ l $(11 \%)$ and piperitenone oxyde (8\%) whereas $L$. rugosa leaves oil is mainly constituted of thymol (26.7\%), p-cymene (15.5\%), thymol acetate (13.2\%) and $\gamma$-terpinene (9.4\%). L. rugosa exhibited the lowest MIC value in liquid medium ranged from 0.2 to $0.3 \mathrm{mg} / \mathrm{ml}$ against all fungal strain, and $P$. glandulosus which was less active with value ranged from 0.8 to $1 \mathrm{mg} / \mathrm{ml}$ against all fungal strain. The antiradical activity of $L$. rugosa essential oil $\left(\mathrm{SC}_{50}=6.7 \mathrm{~g} / \mathrm{l}\right)$ was less than that of butylated hydroxyl toluene $(\mathrm{BHT})$ which was used as the reference compound $\left(\mathrm{SC}_{50}=0.007 \mathrm{~g} / \mathrm{l}\right)$. Results obtained in the present study indicate the possibility of exploiting these essential oils in the fight against strains of $A$. flavus, $A$. niger and Fusarium moniliforme responsible for biodeterioration of stored food products.
\end{abstract}

Keywords: Essential oils, Chemical composition, Antifungal activity, Antiradical activity.

\section{INTRODUCTION}

The invasion of various food commodities by fungi causes considerable losses in tropical and subtropical countries. Fusarium and Aspergillus species are common maize pathogens. Among them, Fusarium moniliforme Sheldon, Aspergillus flavus Link and Aspergillus niger have high specialisation on crops, causing sometime stem and ear rot (McGee, 1988). They are worldwide distributed, mainly in tropical and subtropical areas and have a high survival and a great toxicity (Bacon and Nelson, 1994; Gourama. and Bullerman, 1995). Fungal infections can discolour grain, change its chemical and nutritional characteristics, reduce germination and, most importantly, contaminate it with mycotoxins, such as aflatoxins, and fumonisins which are highly toxic to man and animals (Bennett and Klich, 2003). Conversely, free radical oxidation of the lipid components in food due to chain reactions is a major strategic problem for food manufacturers. Free radicals can initiate the destruction of organic molecules of biological importance and are regarded as the cause of various diseases and probably ageing (Halliwell and Gutteridge, 1989). Due to the health-hazardous effects of free radicals in human beings, it is essential to decrease the degree of lipid peroxidation in foods.

To manage post harvest losses and diseases caused by free radicals, producers usually rely on a release of chemical fungicides (group of benzimidazoles, aromatic hydrocarbons) and synthetic antioxidants, such as butylated hydroxyanisole (BHA) and butylated hydroxytoluene (BHT). However these chemicals have restricted use in foods as they are suspected to be carcinogenic (Madavi and Salunkhe, 1995).

Public awareness of these risks has gone a long way to increase people's interest in the quest for safer fungicides and antiradicals to replace synthetic chemical fungicides. One of such alternatives is the use of natural plant preservatives such as essential oils, to prevent the proliferation of fungi or protect food from oxidation. Lippia rugosa and Plectranthus 
glandulosus are a potential source of essential oils in Cameroon and other tropical areas (Ngassoum et al., 2001; Ngassoum et al., 2005; Tatsadjieu et al., 2008). L. rugosa is a robust woody perennial plant of the Verbenacea family up to 12 feet high with large oblong-lanceolate bluish- green leaves, pleasant aromatic flowers (Oliver - Bever, 1982). P. glandulosus (Lamiacea) is plant whose leaves are commonly used to protect stored grains, as mosquito repellent and anthelminthic in Cameroon (Nukenine et al., 2003). In the Adamaoua province, the plant is used in folk medicine for treatment of colds and sore throat (Ngassoum et al., 2001). This paper describes the chromatographic examination of the volatile oils extracted from these plant materials as well as bioassays for evaluating their antifungal activities against Aspergillus flavus, Aspergillus niger and Fusarium moniliforme, and antiradical activities.

\section{MATERIAL AND METHODS}

Organisms: The strains of Aspergillus flavus, Aspergillus niger, and Fusarium moniliforme, isolated from maize collected in 2008 at Ngaoundéré (Cameroon) according to the method used by Foko and Sougnabé (1991), maintained in the culture collection of Microbiology Laboratory of the National School of Agro-Industrial Sciences (The University of Ngaoundéré, Cameroon) were used as test microorganisms. They were grown on Sabouraud dextrose agar (Difco, Detroit, MI) plate at $25^{\circ} \mathrm{C}$ for 5 days. Ten millilitres of $1 \%$ Tween 20 were added for spores' collection. The spore suspensions were further adjusted with sterile $1 \%$ Tween to give a final concentration of $10^{6}$ spores $/ \mathrm{ml}$. Spore concentration was determined with a haemocytometer. The suspensions were stored at $4^{\circ} \mathrm{C}$ until used.

Plant material and extraction procedure: The essential oils tested were extracted by water steam distillation using a Clevenger apparatus from the leaves of $L$. rugosa and $P$. glandulosus. Fresh leaves of $L$. rugosa were collected in March 2008 at MBE (dry season) and leaves of $P$. glandulosus were collected in July 2008 at Ngaoundéré located in the Vina Division of the Adamawa region of Cameroon. The distilled essential oils were dried over anhydrous sodium sulphate and stored in a refrigerator at $4^{\circ} \mathrm{C}$.

Chemical analysis: The essential oil obtained was analysed by gas chromatography (GC) and gas chromatography coupled with mass spectrometry (GC/MS).
Gas chromatography: The oil was analysed on a Varian CP-3380 GC with flame ionization detector fitted with a fused silica capillary column (30 m x 0.25 $\mathrm{mm}$ coated with DB5, film thickness $0.25 \mu \mathrm{m}$ ); temperature program $50-200^{\circ} \mathrm{C}$ at $5^{\circ} \mathrm{C} / \mathrm{min}$, injector temperature $200^{\circ} \mathrm{C}$, detector temperature $200^{\circ} \mathrm{C}$, carrier gas $\mathrm{N}_{2}, 1 \mathrm{ml} / \mathrm{min}$. The linear retention indices of the components were determined relative to the retention times of a series of $n$-alkanes and the percentage compositions were obtained from electronic integration measurements without taking into account relative response factors.

GC/MS analyses were performed using a HewlettPackard apparatus equipped with an HP1 fused silica column (30 m x $0.25 \mathrm{~mm}$, film thickness $0.25 \mu \mathrm{m})$ and interfaced with a quadrupole detector (GCquadrupole MS system, model 5970). The column temperature was programmed from $70-200^{\circ} \mathrm{C}$ at $10^{\circ} \mathrm{C} / \mathrm{min}$; injector temperature was $200^{\circ} \mathrm{C}$. Helium was used as the carrier gas at a flow rate of 0.6 $\mathrm{ml} / \mathrm{min}$; the mass spectrometer was operated at 70 $\mathrm{eV}$.

Identification of components: The identification of the constituents was assigned on the basis of comparison of their retention indices and their mass spectra with those given in the literature (Adams, 2007).

Minimum Inhibitory Concentration (MIC): Antifungal assay was performed using the agar disc diffusion method (De Billerbeck et al., 2001). Potato dextrose agar (PDA) medium with different concentrations of essential oils $(0.1,0.2,0.3,0.4,0.5$, $0.8,1$ and $2 \mathrm{mg} / \mathrm{ml}$ ) were prepared by adding the appropriate quantity of essential oil/compound to the melted medium, followed by manual rotation of the Erlenmeyer flask to disperse the oil in the medium. About $20 \mathrm{ml}$ of the medium was poured into glass Petri-dishes $(9 \mathrm{~cm} \times 1.5 \mathrm{~cm})$. Each Petri-dish was inoculated at the centre with a mycelia disc $(6 \mathrm{~mm}$ diameter) taken at the periphery of a fungal strain colony grown on PDA for $48 \mathrm{~h}$. Control plates (without essential oil) were inoculated following the same procedure. Plates were incubated at $30^{\circ} \mathrm{C}$ and the colony diameter was recorded each day. Minimal inhibitory concentration (MIC) was defined as the lowest concentration of essential oil in which no growth occurred. For each concentration, three tests were carried out.

Evaluation of antiradical activity: The antiradical activity was determined using 2,2-diphenyl-1picrylhydrazyl (DPPH) Brand-Williams et al, (1995), 
Agric. Biol. J. N. Am., 2011, 2(11): 1362-1367

free stable radical scavenger, which was dissolved in ethanol to give a $100 \mu \mathrm{M}$ solution. To $2 \mathrm{ml}$ of the ethanolic solution of DPPH was added $100 \mu \mathrm{l}$ of a methanolic solution of an antioxidant reference $(\mathrm{BHT})$ at different concentrations. The oil was tested using the same method. The control without antioxidant is represented by the DPPH ethanolic solution containing $100 \mu \mathrm{l}$ of methanol. The decrease in absorption was measured at $517 \mathrm{~nm}$ after 1 hour at room temperature. The actual decrease in absorption induced by the test compound was calculated by subtracting that of the control. The concentration required for $50 \%$ reduction $\left(\mathrm{RSC}_{50}\right)$ was determined graphically. All the spectrophotometric measurements were performed with a SAFAS UV$\mathrm{mc}^{2} \quad$ spectrophotometer, equipped with a multicell/multikinetics measuring system and with a thermostated cell-case.

Statistical analysis: Data from three independent replicate trials were subjected to statistical analysis using Statistica .06, Statistical package (Statsoft, 1995). Differences between means were tested using Duncan Multiple Range Test.

\section{RESULTS AND DISCUSSION}

Chemical constituents of the essential oils: Essential oils were obtained by steam distillation for 5 hours with a yield of $1.8 \%(\mathrm{w} / \mathrm{w})$ and $0.40 \%(\mathrm{w} / \mathrm{w})$ respectively for $L$. rugosa and $P$. glandulosus. The volatile constituents of the different oils were identified by their retention index and mass spectrum in comparison with those of standard synthetic compounds. The results of the chemical analysis are presented in Table 1. These results revealed that the oil from $L$. rugosa is mainly constituted of monoterpenoids with the most important constituents identified as thymol (26.7\%), p-cymene (15.5\%), thymol acetate (13.2\%) and $\mathrm{y}$-terpinene $(9.4 \%)$ whereas $P$. glandulosus oil is mainly constituted of terpinolene $(30.8 \%)$, fenchone $(13.2 \%)$, terpene 4 -ol $(11 \%)$ and piperitenone oxyde $(8 \%)$. The profile obtained from our GC and GC-MS analysis of $L$. rugosa essential oil was quantitatively different from that reported by Ngassoum et al, (2005) and Tatsadjieu et al, (2008) who found that L. rugosa leaves collected from Ngaoundere was mainly constituted of geraniol (51.6\%), nerol (18.2\%), geranial (10.8\%) and Linalool (4.6\%). That difference in the chemical composition confirmed the fact that the chemical compounds of any plant essential oil can vary greatly with geographical region, the age of the plant, local climatic, seasonal and experimental conditions (Regnault-Roger and Hamaraou 1995; Daferara et al., 2000).

Minimal Inhibitory Concentration (MIC): There are significant differences in the mycelia growth of oilsupplemented samples compared with the control (ANOVA and Duncan Multiple Range Test, $\mathrm{P}<0.05$ ). $L$. rugosa essential oil exhibited the lowest MIC values with $0.2 \mathrm{mg} / \mathrm{ml}$ against $F$. moniliforme and 0.3 $\mathrm{mg} / \mathrm{ml}$ against $A$. flavus, $A$. niger; (table 2). Essential oil from $P$. glandulosus was less active with 0.8 $\mathrm{mg} / \mathrm{ml}$ against $F$. moniliforme; $1 \mathrm{mg} / \mathrm{ml}$ against $A$. flavus and $A$. niger. Growth inhibition was significantly $(P<0.05)$ influenced by the incubation time and essential oil concentration. Mycelia growth was considerably reduced with increasing concentration of essential oil while their growth increased with incubation time.

The results obtained show that $L$. rugosa essential oil was more active in inhibiting mycelia growth of these fungi than $P$. glandulosus. The difference observed in activity between these essential oils can be explained by their chemical composition difference. Reports have indicated that biological activity of essential oil is depended on his chemical composition (Mirsha and Dubey 1994; Amvam et al., 1998; Tagne et al., 2000). The antifungal activity of essential oil is related mainly to its proportion in oxygenated monoterpens (OMT). The antimicrobial activity has also been attributed to the presence of some active constituents in the essential oil such as geraniol, citral, thymol, eugenol and citronellol. Our GC-SM analysis revealed $50.5 \%$ and $47.9 \%$ of oxygenated monoterpens respectively in $L$. rugosa and $P$. glandulosus essential oils. Geraniol was found to be effective in suppressing $A$. flavus growth at $500 \mathrm{mg} / \mathrm{l}$ (Mahmoud, 1999). Authors reported that citral, geraniol and citronellol showed antifungal activities among terpenoids (Viollon and Chaumont 1994). Earlier study found eugenol to be the active compound responsible for fungal inhibition produced by clove essential oil (Bullerman et al., 1977) but the authors raised the possibility that interactive effects of other compounds present in smaller quantities may also contribute. Although in minor percentages, these compounds together with the main compounds identified can be considered as the antifungal constituents of these essential oils. 
Table 1: Chemical constituents of the essential oils from $L$. rugosa and $P$. glandulosus leaves collected from the Adamawa region of Cameroon

\begin{tabular}{|c|c|c|c|}
\hline \multirow{2}{*}{ Compound } & \multicolumn{2}{|c|}{ Percentage } & \multirow[t]{2}{*}{ IK } \\
\hline & L. rugosa & P. glandulosus & \\
\hline MTH & 41.2 & 44.7 & \\
\hline$\alpha$-thujene & 2.2 & - & 926 \\
\hline a-pinene & 0.6 & 0.4 & 935 \\
\hline Sabinene & 0.6 & - & 970 \\
\hline$\beta$-pinene & 0.1 & - & 977 \\
\hline Myrcene & 4.9 & 1.5 & 983 \\
\hline$\alpha$-phellandrene & 1.9 & - & 1002 \\
\hline$\Delta 3$-carene & 0.1 & 1.5 & 1008 \\
\hline$\alpha$-terpinene & 0.2 & 0.3 & 1011 \\
\hline p-cymene & 15.5 & 2.6 & 1018 \\
\hline Limonene & 4.7 & 6.2 & 1027 \\
\hline E- $\beta$-ocimene & 0.2 & 0.3 & 1038 \\
\hline Z- $\beta$-ocimene & 0.2 & - & 1039 \\
\hline$y$-terpinene & 9.4 & 0.5 & 1055 \\
\hline Terpinolene & 0.2 & 30.8 & 1085 \\
\hline$\alpha$-terpinolene & 0.4 & 0.6 & 1096 \\
\hline MTO & 50.5 & 47.9 & \\
\hline Linalool & 2 & - & 1088 \\
\hline fenchone & 0.4 & 13.2 & 1079 \\
\hline$\alpha$-fenchol & - & 0.4 & 1105 \\
\hline Fenchol & - & 0.5 & 1127 \\
\hline geraniol & 1.7 & 4.6 & 1238 \\
\hline camphor & - & 1.1 & 1132 \\
\hline E-pinocarveol & 0.1 & - & 1136 \\
\hline isoborneol & 0.2 & - & 1159 \\
\hline Borneol & - & 0.4 & 1166 \\
\hline terpene 4-ol & 0.5 & 11 & 1177 \\
\hline Myrtenol & 0.2 & - & 1185 \\
\hline Z-ocimenone & 1.1 & - & 1215 \\
\hline E-ocimenone & 0.8 & - & 1223 \\
\hline carvone & 2.3 & - & 1229 \\
\hline piperitone & - & 1.3 & 1240 \\
\hline géranial & 0.2 & - & 1255 \\
\hline epoxypiperitone & - & 0.3 & 1257 \\
\hline 4-hydroxy piperitone & - & 2.4 & 1284 \\
\hline thymol & 26.7 & 1.9 & 1289 \\
\hline safrole & - & 0.5 & 1301 \\
\hline carvacrol & 0.2 & - & 1309 \\
\hline piperitenone & - & 1.2 & 1333 \\
\hline thymol acetate & 13.2 & - & 1335 \\
\hline carvacrol acetate & 0.1 & - & 1349 \\
\hline piperitenone oxide & - & 8 & 1350 \\
\hline Eugenol & 0.8 & 1.1 & 1353 \\
\hline STH & 7.4 & 4.7 & \\
\hline$\alpha$-copaene & - & 0.4 & 1385 \\
\hline$\beta$-elemene & - & 1.1 & 1395 \\
\hline$\beta$-caryophyllene & 4.2 & 0.6 & 1433 \\
\hline E-caryophyllene & - & 0.5 & 1439 \\
\hline$\beta$-gurjunene & - & 0.4 & 1448 \\
\hline E- $\beta$-farnesene & 2.3 & - & 1449 \\
\hline$\beta$-copaene & - & 0.5 & 1450 \\
\hline a-humulene & 0.7 & 0.4 & 1467 \\
\hline germacrene D & 0.2 & 0.8 & 1492 \\
\hline STO & 0.5 & 2.2 & \\
\hline humulene oxide & - & 0.9 & 1507 \\
\hline$\beta$-bisadolene & 0.2 & - & 1509 \\
\hline$\Delta$-cadinene & - & 0.3 & 1527 \\
\hline Nerolidol & - & 0.3 & 1562 \\
\hline caryophyllene oxyde & 0.3 & - & 1594 \\
\hline a-cadinol & - & 0.7 & 1676 \\
\hline
\end{tabular}


Table 2: MIC (mg/l) of Essential oils

\begin{tabular}{|l|c|c|}
\hline Fungal species & \multicolumn{2}{|c|}{$\begin{array}{c}\text { Minimal Inhibitory Concentration } \\
\text { (mg/ml) }\end{array}$} \\
\hline & L. rugosa & P. glandulosus \\
\hline A. flavus & 0.3 & 1 \\
\hline A. niger & 0.3 & 1 \\
\hline F. Moniliforme & 0.2 & 0.8 \\
\hline
\end{tabular}

Antiradical activity: Antioxidants are believed to intercept the free radical chain of oxidation and to give hydrogen from the phenolic hydroxyl groups, thereby forming stable end product, which does not initiate or propagate further oxidation of lipid (Sherwin, 1998). In the present study, results focalised on $L$. rugosa essential oil are expressed as the ratio percentage of the absorbance decrease of DPPH radical solution in the presence of extract at
$517 \mathrm{~nm}$ to absorbance of DPPH radical solution at the same wavelength. Generally, it was observed that the scavenging capacity of the essential oil and BHT increase with their concentrations in the reaction medium. It can be observed from table 3 that $L$. rugosa exhibited weak radical scavenging capacity (RSC). The following results were obtained: $\mathrm{RSC}_{50}$ $(\mathrm{BHT})=0.007 \mathrm{~g} / \mathrm{l}$ and $\mathrm{RSC}_{50}$ (essential oil) $=6.7 \mathrm{~g} / \mathrm{l}$ ). These results indicate that $L$. rugosa essential oil is less active than the BHT. This oil showed a less RSC than those of Plectranthus grandis and Plectranthus ornatus (Albuquerque et al., 2006) Lauris nobilis and Foeniculum vulgare susp. piperitum (Conforti et al., 2006). This lower RSC of $L$. rugosa essential oil could be explained by the absence of compounds able to form stable free radical after losing protons.

Table 3: Scavenging activity of $L$. rugosa essential oil on DPPH

\begin{tabular}{|c|l|l|}
\hline Concentration (mg/l) & Essential oil & BHT \\
\hline 0 & Inhibition percentage $^{{ }^{a}}$ & Inhibition percentage $^{{ }^{\text {a }}}$ \\
\hline 2.5 & 0 & 0.00 \\
\hline 5 & - & 22.35 \\
\hline 10 & - & 40.23 \\
\hline 20 & - & 63.97 \\
\hline 30 & - & 88.58 \\
\hline 40 & - & 98.14 \\
\hline 2500 & - & 100 \\
\hline 5000 & 25,7 & - \\
\hline 10000 & 45,7 & - \\
\hline 20000 & 58,7 & - \\
\hline 25000 & 72,8 & - \\
\hline & 83,0 & - \\
\hline $\mathrm{SC}_{50}(\mathrm{mg} /)^{\mathbf{b}}$ & 94,4 & \\
\hline
\end{tabular}

a Mean values obtained from experiments performed in triplicate.

b Mean value determined graphically

Conclusion: From these results, it can be concluded that the essential oil of $L$. rugosa and $P$. glandulosus showed interested antifungal activity against Aspergillus flavus, Aspergillus niger, and Fusarium moniliforme which are responsible for food spoilage. As far as antioxidant activity concerned, L. rugosa essential oil showed very weak activity when compared to BHT. For the practical use of this oil as novel fungal control agent, further research is needed on the formulation to improve the fungicidal potency and stability.

\section{ACKNOWLEDGEMENTS:}

Authors are grateful to the University of Ngaoundéré - Cameroon for its financial support through "The
University Research Program", Research Grant No. 788/UN/R/VR - RC/DAAC/ DRD/SR.

\section{REFERENCES}

Adams, R.P (2007). Identification of Essential Oils by Gas Chromatography Quadrupole Mass Spectrometry. $4^{\text {th }}$ edition, Allured: Carol Stream, USA 804p.

Albuquerque, R.L., Vasconcelos, SMGD., Machado, M.I.L., Matos, F.J.A., Morais, S.M.D. and Neto, J.S (2006). Chemical composition and antioxidant activity of Plectranthus grandis and $P$. ornatus essential oils from north-eastern Brazil. Flav. Frag. J. 22: 24-26.

Amvam Zollo, P.H., Biyiti, L., Tchoumbougnang, F., Menut, C., Lamaty, G. and Bouchet Ph (1998). Aromatic Plants of Tropical Central Africa. Part XXXII. Chemical Composition and Antifungal Activity of Thirteen 
Essential Oils from Aromatic Plants of Cameroon. Flav. Frag. J 13: 107-114.

Bacon, C.W. and Nelson, P.E (1994). Fumonisin production in corn by toxigenis strains of Fusarium moniliforme and Fusarium proliferatum. J. Food Protect, 57: 514-521.

Bennett, J.W. and Klich, M (2003). Mycotoxins. Clin. Microbiol. Rev; 16: 497-516.

Brand-Williams, W., Cuvelier M.E. and Berset C (1995). Use of free radical method to evaluate antioxidant activity. Lebensm. Wiss. und Technol 28: 25-30.

Bullerman, L.B., Lieu, F.Y. and Seire, A.S (1977). Inhibition of growth and aflatoxin production by cinnamon and clove oils, cinnamic aldehyde and eugenol. J. Food Sci 42: 1107-1116.

Conforti, F., Statti, G., Uzunov, D. and Menichini, F (2006). Comparative chemical composition and antioxidant activities of wild and cultivated Laurus nobilis L. leaves and Foeniculum vulgare sub sp. piperitum (Ucria) Coutinho seeds. Biol. Pharm. Bull. 29: 2056-2064.

Daferara, D.J., Ziogas, B.N. and Polissiou, M.G (2000). GC-MS analysis of essential oil from Greek aromatic plants and their fungitoxicity on Penicillium digitatum. J.Agric. Food Chem 48: 2576-2581.

De Billerbeck, V.G., Roques C.G., Bessière, J.M., Fonvieille, J.L. and Dargent, R (2001). Effect of Cymbopogon nardus (L) W. Watson essential oil on the growth and morphogenesis of Aspergillus niger. Can. J. Microbiol 47: 9-17.

Foko J. and Sougnabe (1991). Composition sites d'infection et Evolution de la spermoflore fongique de l'Arachide dans le bassin du mayo-kebbi (Tchad). Biosci. Proc. 2: 314-317.

Gourama, H. and Bullerman, L.B (1995). Antimycotic and antiaflatoxigenic effect of lactic acid bacteria. Journal of Food Protection; 57: 1275-1280.

Halliwell, B. and Gutteridge, J.M.C (1989). Free radicals in biology and medicine. Oxford: Clarenson Press.

Madavi, D.L. and Salunkhe, D.K (1995). Toxicological Aspects of Foods Antioxidants. In: Food Antioxidants. Madavi, D.L., S.S

Mahmoud, A.L.E (1999). Inhibition of growth and aflatoxin biosynthesis of Aspergillus flavus by extract of some Egyptian plants. Lett. Appl. Microbiol 29: 334-336.

McGee, D (1988). Maize diseases: a reference source for seed technologist. St. Paul, Minnesota. APS Press, 13-15.

Mirsha, A.K. and Dubey, N.K (1994). Evaluation of some essential oil for their toxicity against fungi causing deterioration of stored food comodities. Appl. Env. microbiol 160: 1101-1105.

Ngassoum, M.B., Jirovetz, L., Buchbauer, G. and Fleischhacker, W (2001). Investigation of essential oil of Plectranthus glandulosus Hook $\mathrm{f}$. (Lamiaceae) from Cameroon. J. oil Res. 13: 73-75.

Ngassoum, M.B., Tatsadjieu, L.N., Mapometsem, P.M., Jirovetz, L., Buchbauer, G. and Shahabi, M (2005). Comparative aroma compound analysis of different essential oils of Lippia rugosa from Cameroon using GC-FID, GC-MS and olfactometry. J. Ess. Oil Res. 17: 492-495.

Nukenine, E.N., Mebanga, A.S., Njan Nloga, A.N., Fontenille, D., Nchoutpouen, E. and Tepamdi, M (2003). Culicid diversity and plant materials used as mosquito repellents in northen Cameroon. Paper presented at the $15^{\text {th }}$ Conference of the African Association of Insect Scientists (AAIS) and the Entomological Society of Kenya, 9-13 June, Nairobi, Kenya. Book of Abstract.

Oliver - Bever, B (1982). Medicinal plant in West Africa pp. 32-33. Cambridge University Press.

Regnault-Roger, C. and Hamaraou, A (1995). Fumigant toxic activity and reproductive inhibitory induced by monoterpenes on Acathoscelides obtectus (Say) (Coleoptera) bruchid of kidney bean (Phaseolus vulgaris L.). J. Stored Prod. Res 31: 291-299.

Sherwin, E.R (1998). Oxidation and antioxidants in fat and oil processing. J. Am. Oil Chem. Sci 55: 809-814.

Statsoft. Statistica for Windows. SPSS Inc. USA. 1995.

Tagne, A., Nguefack, J., Nangmo, R. and Amvam Zollo, P.H (2000). Natural control of fungi and mycotoxin in grains - a possible means of reducing humain and animal contamination. J. Appl. Sci. in Southern Africa 6: $37-44$

Tatsadjieu, N.L., Etoa, F-X., Mbofung, C.M.F. and Ngassoum, M.B (2008). Effect of Plectranthus glandulosus and Ocimum gratissimum on growth of Aspergillus flavus and Aflatoxin B production. Tropicult. 26: 78-83

Viollon, C. and Chaumont J.P (1994). Antifungal properties of essential oils and their main components upon Cryptococcus neoformans. Mycopathol 128: 151-153. 